\title{
Women's Underrepresentation in Management Positions: Evidence from Ethiopia
}

\author{
Yigerem Terefe $^{1} \quad$ Meseret Ketema $^{2} \quad$ Berhan Girma $^{3}$ \\ 1. Senior Management Consultant, Ethiopian Management Institute, Ethiopia \\ 2. Senior Quality Experts, Ethiopian Management Institute, Ethiopia \\ 3. Junior Management Consultant, Ethiopian Management Institute, Ethiopia
}

\begin{abstract}
In the Ethiopian Public Sector, although the presence of women professionals considerably improved in the last two decades, women remained underrepresented in the management positions. In addition to external barriers that women face, their own aspiration that they have towards management positions also explain this underrepresentation in management positions. This study initiated with the objective of investigating the existing difference in aspiration towards management positions between men and women professionals. The total of 312 usable questionnaires was collected form professionals randomly selected from 13 federal public service organizations and for the purpose of analysis AMOS version21 software was employed. The study result depicted that though there was no statistically significant difference between men and women in their desired aspiration, men has greater enacted aspiration than women towards management position. In addition, Men had more management position congruence than women. And the effect of self-management position congruence on enacted aspiration is fully mediated through desired aspiration for both men and women professionals. And this indirect effect of self-management position congruence on enacted aspiration was stronger for men than for women. Hence, the study recommends that the public sector and stakeholders should work on changing Women's low perception about their compatibility with management position in order to enhance their low engagement in behaviors and actions to peruse their desired aspiration to management positions.
\end{abstract}

Keywords: Desired Aspiration, Enacted Aspiration

DOI: $10.7176 / \mathrm{EJBM} / 11-13-02$

Publication date:May $31^{\text {st }} 2019$

\section{BACKGROUND OF THE STUDY}

Despite gains in every profession, women remain underrepresented in management positions. The global trend indicated that women participation in both public and private employment has significantly increased during the last decades. But the increment primarily occurred to proportion of women at entry level, while the proportion of women as we ascend to the highest career ladder has remained relatively lower (ILO, 2002; Afza and Newaz, 2008).

In Ethiopia, a very few number of managerial positions are being filled by women. Out of the total number of managers in the country by occupation $(231,211)$, only $61,308(26.5 \%)$ are women. But the number of women in clerical and support workers outweigh the number of men. Out of the total clerical and support workers in the country $(221,028), 143,331(65 \%)$ are women employees. Out of the total service and sales workers $(3,670,391)$, $2,394,614(65 \%)$ of them are women workers (CSA, 2013).

This underrepresentation of women in management positions can be broadly categorize into two, demand and supply-side factors (Francesca et al., 2015). Accordingly demand side factors encompass the external barriers that women face because of the divergent ways in which men and women are perceived and treated by others and they are part of the environment the individual interacts with. On the other hand supply side factors refers to the aspiration that encompasses attitude and behavior that men and women have towards management positions and they are differences in the perceptions held, decisions made, or behaviors enacted by men and women themselves that contribute to gendered outcomes. And the focus of this study was supply side factors, aspiration to management positions.

Thus, this study was to investigate the existing gender disparities in management positions aspiration and also analyze to what extent compatibility, accessibility and occupational commitment affect management position aspiration for male and female professional groups via employing data from Ethiopian particularly from the public sector.

\section{STATEMENT OF THE PROBLEM}

Great deal of research has provided evidence that bias and discrimination give rise to and perpetuate this gender disparity. But recent studies indicated that, in addition to the external barriers that make women not to be equally represented in management position, the variability in the numbers of women in management positions has also been explained by differences in aspirations for advancement to management positions (Greenhaus et al., 1997; Parasuraman \& Greenhaus, 1992). 
Though existing supply side studies reveled that aspiration is an important factor in career advancement to management positions (Goffee \& Scase, 1992; Hede \& Ralston, 1993; Mael et al., 2001), the number of studies examining management aspirations as a dependent variable are scant in the literature (Litzky, 2002), particularly with regard to sub-Saharan Africa. And in recent years, studies focusing on the supply side factors are getting researchers attention (Francesca et al., 2015). But, there are inconsistencies in the existing literatures in the area, in terms of measurement, conceptualization and imperial findings.

In terms of measurement and conceptualization, single and two items measure by conceptualizing aspiration to a mere attitudinal perspective, that is, the desire for a certain position are most commonly found in the literature (Sloan, 1993; Steiner \& Farr, 1986; Stout et al., 1988; Tremblay \& Roger, 1993) but on the other hand there are also studies that used multiple measures by conceptualizing aspiration as a dual-faceted construct with both attitudinal and behavioral components, that is, desired and enacted aspiration, respectively (Tharenou, 2001; Tharenou \& Terry, 1998). In this study was to investigate the supply side factor, aspiration, by conceptualizing management aspiration as dual-faceted construct.

Studies also lack consistency in their empirical findings as to whether there exists significant gender difference in career promotional desire to management positions. Scholars like Hudson (2008), revealed that there is no statistically significant difference between women and men in career promotional desire to management positions. On the contrary, other scholars found statistically significant difference in career promotional desire between women and men (Vanhala, 2011; Anna, 2013; Francesca et al., 2015).

The purpose of this study was to investigate the existing gender disparity in management promotion aspiration by studding sampled professionals from the selected federal public organizations in Ethiopia.

\section{OBJECTIVES OF THE STUDY}

The General Objective

The overall objective of this study was to investigate the gender disparity existed in professionals' management promotion aspiration.

\section{THE SPECIFIC OBJECTIVES}

The specific research objectives are:

1. To assess the existing difference in desired and enacted aspiration to management positions between women and men professionals in the public sector.

2. To investigate the association between the variables; desired and enacted aspiration for women and men professionals in the public sector.

3. To analyze the effect of perceived self-management position congruence (compatibility), perceived management position advancement prospect (accessibility) and occupational commitment on enacted aspirations for women and men professionals in the public sector.

\section{HYPOTHESIS}

HO1: There is no statistically significant difference in desired aspiration to management position between men and women

HO2: There exist statistically significant difference in enacted aspiration to management position between men and women

HO3: The positive effect of desired aspirations on enacted aspirations is stronger for men than for women.

HO4: The positive effect of independent variables (perceived self-management position congruence, occupational commitment and advancement prospect) on the dependent variable, desired aspiration is stronger for men than women.

HO5: The positive effect of independent variables (perceived self-management position congruence, occupational commitment and advancement prospect) on the dependent variable, enacted aspiration is stronger for men than women.

HO6: Desired aspiration mediates the relationship between the independent variables (perceived selfmanagement position congruence, occupational commitment and advancement prospect) on the dependent variable, enacted aspiration.

\section{SCOPE OF THE STUDY}

Management aspiration can apply for professionals to become managers as well as managers to be promoted for higher position. But this study focused on management aspiration of professionals found at deferent career ladder in federal public organizations. Though management aspiration conceptualized and measured differently, in this study management aspiration conceptualized as a dual-faceted construct with both attitudinal and behavioral components, that is, desired and enacted aspiration, respectively and measured accordingly.

Quantitative research approach was employed to address the research objectives. Hence, structured 
questionnaire was used to collect the required data and both descriptive and inferential statistics was employed for the purpose of analysis.

\section{SIGNIFICANCE OF THE STUDY}

This research finding revealed that the existing gender difference in career promotion specifically to and management positions and those factors that determine promotional aspiration to management positions. Hence, this study help policy makers' to have new orientation in formulation and implementation gender mainstreaming policy that could enhance women's participation in management positions in the public sector.

Moreover, the study benefits feminist actors in that it helps to realize factors that affect their representation in management position and by suggesting how to overcome it. The study also helps other researchers and trainers as empirical evidence to do further research or conduct training in the area.

\section{LEATRATURE REVIEW}

\section{Theoretical framework}

\section{Management Aspirations}

In terms of measurement, management aspirations has been measured primarily as single items asking respondents to indicate a hierarchical level on a checklist to which they ultimately aspire (Judge et al., 1995), to indicate whether they would like to move into a management position (Martin et al., 1987; Rynes et al., 1988). And later, some researchers introduced two-item measures of management aspiration that include a combination of items asking respondents (1) to indicate their preferences for moving into a position in management and (2) to rate the importance of such a move (Sloan, 1993; Steiner \& Farr, 1986; Stout et al., 1988; Tremblay \& Roger, 1993). However, these single and two items measure limits aspiration to a mere attitudinal perspective that is, the desire for a certain position, and excludes other perspectives of managerial aspiration.

Finally, researchers suggest that aspiration may have more components and should thus be conceptualized beyond mere desire (Tharenou, 2001; Tharenou \& Terry, 1998). According to the expectancy theory (Vroom, 1964), people who desire to have something are likely to engage in behavior that helps them acquire it and satisfy their desire. Therefore, Tharenou and Terry (1998) conceptualize aspiration as a dual-faceted construct with both attitudinal and behavioral components, that is, desired and enacted aspiration, respectively. Desired aspiration represents the attitudinal component of aspiration, the extent of the desire for a higher position. Enacted aspiration represents the behavioral component of aspiration, the extent of the actual actions initiated to pursue the position. The more intense the desired aspiration to achieve a management position, the more actions the individual will initiate to attain a higher managerial position (Litzky and Greenhaus, 2007).

Desired aspiration produces a motivational force that triggers effort and persistence toward managerial advancement. Enacted aspiration reflects the actual actions and strategies associated with position advancement (Tharenou \& Terry, 1998). In other words, enacted aspiration is the behavioral manifestation of desired managerial aspiration.

The measurement of management aspirations used in the present study supports this conceptual definition. Based upon prior work of Tharenou and Terry (1998), the measure includes an attitudinal and a behavioral component. The attitudinal component represents an individual's preferences, desires, and likes regarding a management position, and is called desired aspirations. Desired aspirations represent the emotional component of one's pursuit of a career goal. And the behavioral component, enacted aspirations, includes behaviors that represent one's intention to gain a management position and is influenced by one's desire. Behaviors include career planning, seeking developmental experiences, and improving skills. The items identified were indicative of the strategies associated with managerial aspirations (Tharenou \& Terry, 1998). Thus, enacted aspirations are elements in the plan of action (Locke \& Latham, 1990; Pinder, 1998) one undertakes to achieve the ultimate goal of attaining a management position.

This conceptualization and operationalization of management aspirations used in this study to assess the management position aspirations of individuals that includes both desire and intention to pursue a management position.

\section{Management Aspiration and Related Factors}

Based on Gottfredson's $(1981 ; 1996)$ developmental theory of aspiration, career-related aspiration comes from an individual's assessment of compatibility with a job and accessibility to a job. Therefore, two factors related to aspiration appear in this theory, namely, self-job congruence and perceived advancement prospect. The concept of self-job congruence is developed from the assessment of compatibility. By assessing the compatibility between the image of a job and the image of an individual, an individual can identify his/her most suitable choice. In other words, congruence represents the degree of fit between an individual and a job (Holland, 1997).

One's self-perceived occupational image is a natural outgrowth of his or her environmental experiences (Edgar Schein, 1978). These environmental interactions create an occupational self-concept or paradigm regarding an individual's talents, abilities, motives, needs, attitudes, and values (Schein, 1978). And studies 
suggest that individuals with management aspirations are those who feel that a management position is attainable (Stout et al., 1988).

The concept of a perceived advancement prospect is developed from the assessment of accessibility to a job. The possibility or opportunity of achieving the preferred occupation or position is a factor in an individual's aspiration (Gottfredson, 1981, 1996). The effect of perceived advancement prospect on management aspiration follows the central notion of the expectancy theory (Vroom, 1964).

An individual's tendency to act is guided by his/her expectation of a reward. The extent of the reward in career development is advancement to a higher position. If an individual perceives a higher chance of promotion, he/she takes more action to pursue such position advancement. According to Hall (2002), people are more likely to pursue a position if they think that they are capable of attaining it.

Before an individual starts pursuing a preferred occupation or position, he/she evaluates its accessibility and possibility (prospect) (Gottfredson, 1996). In a study, Litzky and Greenhaus (2007) found that people who perceive a favorable career advancement prospect are more likely to engage in strategies to achieve advancement to senior management position than those who perceive unfavorable career prospects.

The third factor related to aspiration is commitment. Colarelli and Bishop (1990) argue that a committed individual tends to set a high career goal and takes action to achieve it. When an individual feels more affection, involvement, and identification with a his/her job, he/she is more likely to develop himself/herself in that job (Lee, Carswell, \& Allen, 2000; Meyer et al., 1993; Meyer, Stanley, Herscovitch, \& Topolnytsky, 2002).

\section{CONCEPTUAL FRAMEWORK OF THE STUDY}

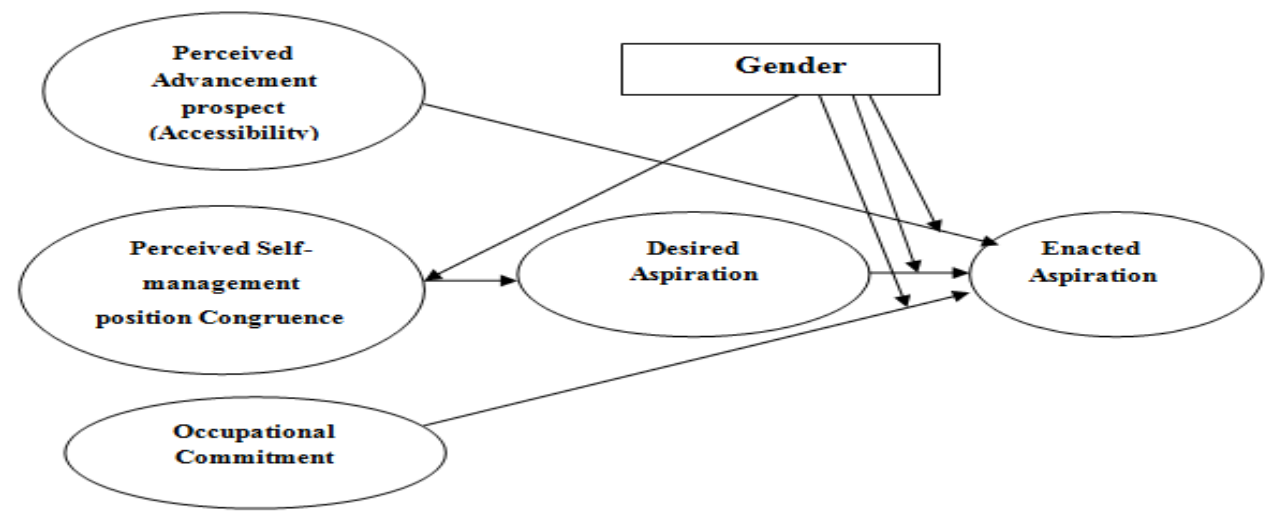

\section{METHODOLOGY}

\section{Research Design}

Since the objective of the study is to compare career related decisions and preferences between women and men, a quantitative research design was employed to meet the research objectives. The benefit of a quantitative method is that it is generalizable, meaning that it is possible to say something about a larger context by studying a meaning that by studying a smaller sample (Saunders et al., 2007). Additionally, this method is easily testable and can be repeated by others getting the same results. In addition similar studies conducted in the area of career related choices have used quantitative approach (Vanhala, 2008; Hudson, 2011; Stavard and Nielsen, 2012).

\section{Data Type and Sources}

For the purpose of the study, primary data was collected from primary sources. Primary data was gathered from professionals found in selected federal public organizations via structured questionnaire.

\section{Sampling Procedure}

For the purpose of selecting sample from the target population which is Federal public Organizations, multistage sampling was employed. In the first stage, sample organizations were selected from the total of 244 Federal public organizations by using random sampling via lottery method. Since Federal Public Organizations and their professionals share similar work culture and behavior the population was considered as homogenous and 5\% (13) organizations are selected as a sample.

In the second stage, from the sampled organizations work processes from which individual professionals were to be selected were identified purposively. As most federal public organizations organized as core and support processes, for the purpose of the study core process were selected purposively. The purpose for selecting core processes is that since the core processes is strategic for an organization, the researchers were interested to investigate professionals form the core processes of the sampled organizations.

In the last stage, sample individual Experts were selected from the selected organizations. For the purpose of the study professionals were selected by using simple random sampling using random number table. The total of 384 Experts were selected as a sample from the selected organizations by using a formula developed by 
Cochran (1963) for determining sample size from large population size.

In order to get adequate sample size to compare men and women experts, equal number of questionnaire were distributed among the sampled organizations (30 questionnaires per organization). And the questionnaires were distributed among the sampled professionals by spiting evenly between the two sex groups using quota sampling.

\section{Sample Size}

For populations that are large, Cochran (1963) developed the following equation to yield a representative sample for proportions. Based on this formula, sample size was determined to be 384 where $(\mathrm{p}=50 \%)$, required level of precision $\left(\mathrm{e}^{2}=0.05\right)$, and confidence level wanted $\left(\mathrm{Z}^{2}=1.96\right)$.

$n=\frac{Z^{2} p(1-P)}{(e)^{2}}$

\section{Method of Data Collection}

The method of data collection used in this study was survey method, and the data collection tool that was employed to gather required data from sampled respondents were structured questionnaire. And the questionnaire had pre coded closed formats. Moreover, since all the respondents were literate, they filled the questionnaire by their own, and this made them to freely express their idea on the issue.

\section{Method of Data Analysis}

For the purpose of data analysis, both descriptive and inferential statistics were employed. Descriptive statistics such as graphs, charts mean, standard deviation, percentages were applied to characterize the sample units.

Inferential statistics like Chi-square, t-test were utilized to analyze the existing difference in between men and women by different study variables. In addition, Econometric Model (Structural Equation Modeling) was applied to validate the measurement model and predict relationship of the structural model.

\section{RESULT AND DISCUSSION}

For the purpose of the study 384 questionnaires were distributed. Respondents were asked to complete the questionnaire within two weeks. And finally, 312 useable questionnaires were returned and analyzed representing a response rate of $81.25 \%$. And the adequacy of the number of observations to run structural equation modeling were checked and Since the study contained 33 variables, the proportion of the observations to variables were approximately 9 to 1 which was by far greater than the recommended proportion which is 5 observation per 1 variable Bentler \& Chou (1987).

\section{Data Screening}

Before proceeding for analysis the data was screened for outliers, unengaged respondents and missing variables for a single respondent. All the observed variables were categorical variables mainly measured by 5 point likert scale and since it was difficult to identify outliers all cases was retained for analysis. The standard deviation for each case was assessed and the minimum value found to be 0.54 , indicating that there were no unengaged cases in the dataset. the maximum percentage of missed variables by a single respondent was $6 \%$. Since it did not exceed $10 \%$, those cases were retained by imputing the missed values using median replacement for likert scale and categorical variables and mean replacement for continues variables.

\section{Exploratory Factor Analysis}

Since the exploratory factor analysis in this particular study deal with a sample for further analysis, principal axis factoring method was employed as appropriate extraction method (Peter Samuel, 2016). And promax rotation, which is an oblique rotation, was used as it allows a degree of correlation as maximum correlation coefficient of factor correlation matrix reached up to 0.543 . Eigenvalues less than 1 was used as a cut off criteria to determine the number of factors to be retained. And items factor coefficients were sorted by size and all factor coefficients less than 0.3 suppressed.

Before passing to EFA, appropriateness of data for EFA was tested. The adequacy of the sample size was tested through Kaiser-Meyer-Olkin (KMO) and the strength of the relationship among variables was assessed through Bartlett's test of sphericity (Pallant, 2013). The sampling is adequate if the value of Kaiser Meyer Olkin (KMO) is larger than 0.6 (Pallant, 2013). Tabel-1 below showed that the Measure of Sampling Adequacy test score was 0.88 , and the sample size was adequate for EFA. And the Bartlett Test of Sphericity was significant at $1 \%$ level of significance as shown in Table 1 below; indicating that the data do not produce an identity matrix and are thus approximately multivariate normal and acceptable for further analysis (Pallant, 2013; Field, 2000).

Table 1: KMO and Bartlett's Test

\begin{tabular}{llr}
\hline Kaiser-Meyer-Olkin Measure of Sampling Adequacy. & & $\mathbf{9 0 9}$ \\
\hline Bartlett's Test of Sphericity & Approx. Chi-Square & 7096.371 \\
& df & 528 \\
& Sig. & 0.000 \\
\hline
\end{tabular}

Source: own computation 
At the beginning of the exploratory factor analysis, there were 33 items that load around 8 factors. And the analysis was started by removing items with low communalities. The common item communalities magnitudes in the social sciences are low to moderate communalities of 0.40 to 0.70 respectively. And item having a communality of less than 0.40 , indicated that it has poor relationship with the remaining items, and should be dropped from the analysis or add similar items for future research (Velicer and Fava, 1998). Based on this recommendation, in this study, 5 items with communality score less than 0.4 were dropped and it was done by removing one item at a time starting from the lowest value and by re-running the analysis again. With this process, the number of items and factors was reduced to 28 and 6 respectively.

The next step was resolving cross loading issues. There were 4 Cross factor loading items that load at 0.32 and higher on more than one factor were dropped (Tabachnick and Fidell, 2001). Finally the number of factors was adjusted and 24 variables with 5 stable factors with the minimum loading of variables under each factor was found to be 0.517 (see Table-2 below). And the 5 extracted factors accounted for $62.173 \%$ of the total variance in the data. According to Streiner (1994), for the factors to be considerd as stable the retained factors should have at least three items with a loading greater than 0.4. And the proportion of the total variance explained by the retained factors should also be noted. As a general rule this should be at least $50 \%$. In addition one item from perceived self-management position congruence construct, I would enjoy doing the things that Managers do, load with another construct, desired aspiration, with the loading value 0.517 .

Table 2: Extracted factors with their indicators

\begin{tabular}{|c|c|}
\hline Factors with their indicators & loading \\
\hline \multicolumn{2}{|l|}{ Occupational Commitment } \\
\hline I am proud to be in this profession & .888 \\
\hline I do identify with my profession & .883 \\
\hline I am contented having entered to my profession & .875 \\
\hline I like my profession & .875 \\
\hline I am enthusiastic about my profession & .837 \\
\hline My current profession is important to my self-image & .715 \\
\hline \multicolumn{2}{|l|}{ Desired Aspiration } \\
\hline Even if promotion to a management position means more worries I don't avoid for that reason & .865 \\
\hline I would like to be in a position in which I could manage the activities of large part of the organization & .834 \\
\hline I have desire to advance to a management positions & .789 \\
\hline I wish to advance to a position of more responsibility & .733 \\
\hline I would like to advance to a position where I can have a greater influence on policy decisions & .574 \\
\hline I would enjoy doing the things that Managers do & .517 \\
\hline \multicolumn{2}{|l|}{ Perceived Self-Management Position Congruence } \\
\hline I would fit in well with other leaders in the organization & .829 \\
\hline My personality fits in well with the requirements of a management position & .757 \\
\hline I have what it takes to be an effective manager & .733 \\
\hline A management position would be a good fit for me & .703 \\
\hline the requirements of a management position match my talents and skills & .633 \\
\hline \multicolumn{2}{|l|}{ Perceived Advancement Prospect } \\
\hline The likelihood that I will get a management position is high & .999 \\
\hline My opportunities for a management position are fairly high & .858 \\
\hline I am likely to obtain leadership position & .623 \\
\hline \multicolumn{2}{|l|}{ Enacted Aspiration } \\
\hline I have demonstrated to a senior person in my organization my willingness to take risk & .654 \\
\hline I have asked to work on challenging assignments & .553 \\
\hline I have improved my critical thinking skills by asking to work on complex problems & .551 \\
\hline I have worked long extra working hours & .526 \\
\hline
\end{tabular}

Source: own computation

Confirmatory Factor Analysis

After factor structure (how the items relate and group based on inter-item correlations) was determined using EFA the next step was to conduct CFA in order to confirm or validate the factor structure extracted in the EFA. The initial confirmatory factor analysis model was developed by taking the factor structure from EFA as an input (see the figure below). And the model was identified by constraining one of the regression weights from each 
factor in to 1. And Maximum Likelihood Estimation method was used to fit the CFA model.

The model fitness was tested to see how well our proposed model (in this case, the model of the factor structure) accounts for the correlations between variables in the dataset. At the beginning the model fit was acceptable but not excellent as wittiness by the model fit measures, CFI. Table 3 indicated that value of CFI was 0.946 which is below the Threshold $>0.95$ ( $\mathrm{Hu}$ and Bentler, 1999). To improve the model fit modification indices were considered. Modification indices offer suggested remedies to discrepancies between the proposed and estimated model. And appropriate modifications were done by co-varying error terms that are part of the same factor as shown on the Figure-1 below.

Figure-1: Confirmatory Factor Analysis Model

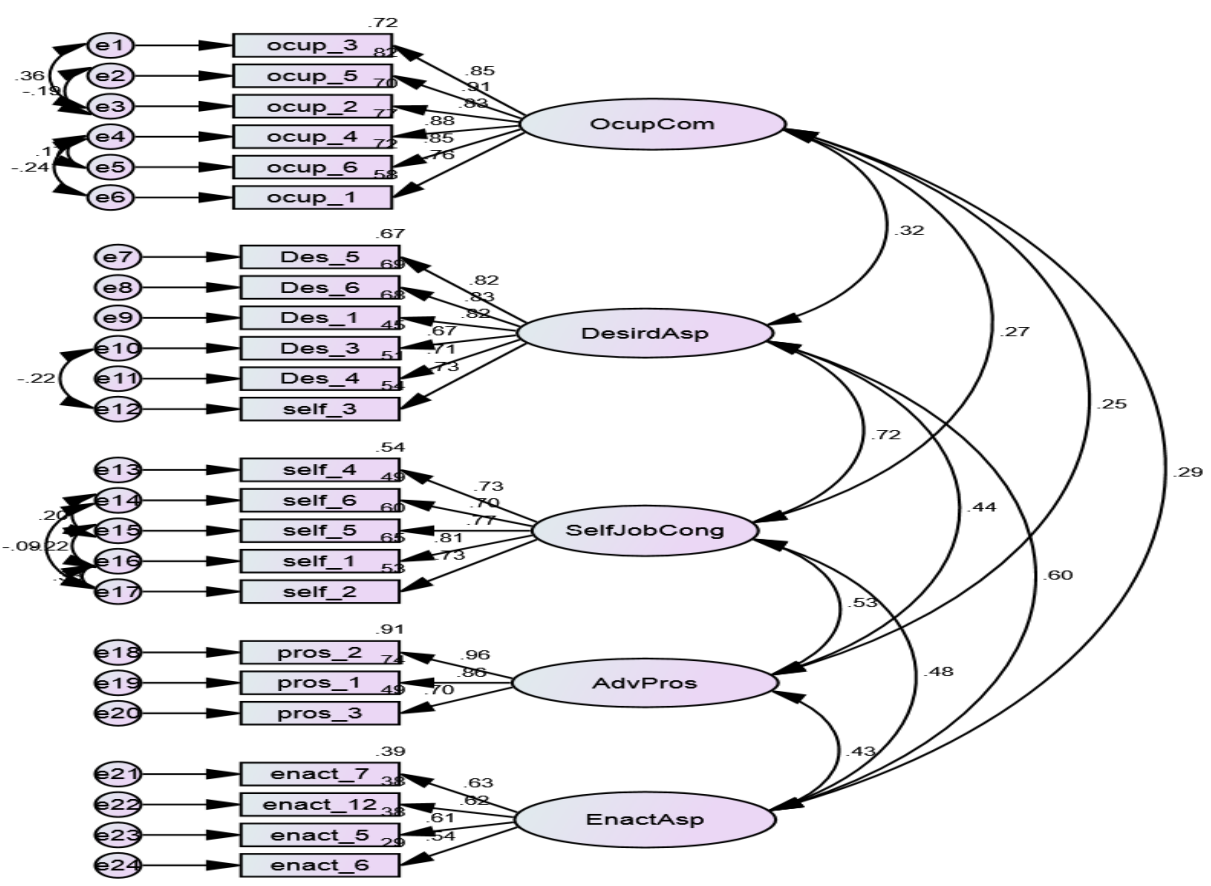

Source: own Computation

By employing this modification CFI improved to the value 0.976 and achieved the threshold level (table 3 ). And the model also improved to excellent model fit.

Table-3: Model Fit Measures

\begin{tabular}{ccccc}
\hline Measure & Estimate & Estimate after modification & Threshold & Interpretation \\
\hline CMIN & 486.626 & 343.454 & -- & -- \\
DF & 242 & 233 & -- & -- \\
CMIN/DF & 2.011 & 1.474 & Between 1 and 3 & Excellent \\
CFI & 0.946 & 0.976 & $>0.95$ & Excellent \\
SRMR & 0.048 & 0.046 & $<0.08$ & Excellent \\
RMSEA & 0.057 & 0.039 & $<0.06$ & Excellent \\
PClose & 0.058 & 0.984 & $>0.05$ & Excellent \\
\hline
\end{tabular}

Source: own computation

Since the study involved multi-group analysis using the grouping variable sex, configural and metric invariance were tested to validate that the factor structure and loadings are sufficiently equivalent across groups.

Configural invariance test was done by splitting the data by sex, and analyzing freely estimated model across the two groups. And it is found that the resultant model achieved good fit (SRMR $=0.055, \mathrm{RMSEA}=$ $0.034, \mathrm{CFI}=0.963$ and Pclose $=1$ ).

Metric invariance test was done by using a chi-square difference and multi-group moderation test using critical ratios for differences. Chi-square difference test was used to test whether there exist a difference between the two groups at model level and it was done by comparing unconstrained model with fully constrained model. Based on the analysis result depicted on Table 4, it was found that there was no statistically significant difference between the two groups, women and men at model level. 
Table 4: chi-square difference test

\begin{tabular}{lcccc}
\hline & chi-square & df & p-val & invariant? \\
\hline unconstrained & 634.843 & 466 & - & - \\
fully constrained & 662.84 & 490 & - & - \\
number of groups & - & 2 & - & - \\
difference & 27.997 & 24 & 0.26 & yes \\
\hline
\end{tabular}

Source: own computation

In addition to chi-square difference test, multi-group moderation test using critical ratios for differences to test whether there existed a difference between the two groups at path level. And the unstandardized regression weight of each items across the two groups were compared and no statistically significant difference were found indicating that the measures are metrically invariant.

\section{Validity and Reliability}

In this study, all of the measurement items represented their factors significantly, as the critical ratio of every item exceeded the 1.96 value at $1 \%$ level of significant; hence, all of the measurement items satisfied the convergent validity test. (Hair, Black, Babin and Anderson, 2006). Convergent validity can also be satisfied if the square root of AVE greater than variance between constructs (Hair, Black, Babin and Anderson, 2006). And as shown in the table 5 , the constructs also satisfied this condition and ensure that all the items of each construct are correlated with each other.

Discriminant validity is the extent to which the items do not correlate with other items of a different construct. The construct satisfy discriminant validity if Maximum shared variance (MSV) is less than Average variance extracted (AVE) (Hair, Black, Babin and Anderson, 2006). As indicated on the table 5 below all the constructs MSV is less than AVE and all the constructs satisfy discriminant validity.

Regarding reliability of the construct, composite reliability (CR) more than 0.7 need to be meet the reliability criteria. And the CR of all the construct is greater than 0.7 except for Enacted variable which is 0.691 (Table 5). This low CR was because of the items having low loadings, and removing those items were recommended to improve the CR. But, since those items are important to measure the concept and since the CR value is closer to 7, the researchers decided to retain the all the items. Another rule of thumb for checking composite reliability is in comparison with squared multiple correlations provided in the Amos output. Composite reliability is considered high if squared multiple correlation R2 greater than 0.5 , moderate if between 0.3 and 0.5 and poor if less than 0.3 (Amos, Holmes and Keneson, 2014). Based on this, the CFA output indicated that 17 items were having high square multiple correlation greater than $0.5,6$ items were moderate between 0.3 and 0.5 and 1 item was poor which is less than 0.3 (see Figure-1 above).

Table 5: Model Validity Measures

\begin{tabular}{llllllllll}
\hline & CR & AVE & MSV & MaxR(H) & OcupCom & DesirdAsp & SelfJobCong & AdvPros & EnactAsp \\
\hline OcupCom & 0.938 & 0.717 & 0.103 & 0.944 & $\mathbf{0 . 8 4 7}$ & & & & \\
DesirdAsp & 0.895 & 0.589 & 0.519 & 0.903 & $0.321^{* * *}$ & $\mathbf{0 . 7 6 7}$ & & & \\
SelfJobCong & 0.865 & 0.562 & 0.519 & 0.869 & $0.274^{* * *}$ & $0.721^{* * *}$ & $\mathbf{0 . 7 4 9}$ & & \\
AdvPros & 0.882 & 0.717 & 0.28 & 0.935 & $0.248^{* * *}$ & $0.441^{* * *}$ & $0.529^{* * *}$ & $\mathbf{0 . 8 4 7}$ & \\
EnactAsp & 0.691 & 0.359 & 0.356 & 0.694 & $0.287^{* * *}$ & $0.597^{* * *}$ & $0.484^{* * *}$ & $0.425^{* * *}$ & $\mathbf{0 . 5 9 9}$ \\
\hline
\end{tabular}

Source: own Computation

Profile of the Respondents by Sex

The study included respondents having work experience ranging from less than 1 year to more than 15 years. Out of the total men respondents, 42(53.8\%), 81(54.7\%), 23(46.9\%), 6(60.0\%) and 9(45.0\%) of them were found to be under $1,1-5,6-10,11-15$ and $>15$ years of work experience respectively. And out of the total women respondents, 36(46.2\%), 67(45.3\%), 26(53.1\%), 4(40.0\%) and 11(55.0\%) of them were having under 1, 1-5, 6$10,11-15$ and $>15$ years of work experience respectively (Table 1). Based on the analysis result, there were no statistically significant difference in work experience between women and men respondents.

Concerning respondents' work position, 22(48.9\%), 46(45.5\%) and 97(59.1\%) of men respondents and 23(51.1\%), 55(54.5\%) and 67(40.9\%) of women respondents were Junior Expert, Expert and Senior Expert respectively (Table 1). And based on the chi-square test, the existing difference in work position between women and men respondent groups were not found to be statistically significant.

With regard to educational status, the respondents' educational status ranges from Diploma to Masters Degree. Table 1 depicted that $5(16.7 \%), 134(57.0 \%)$ and $27(57.4 \%)$ of men respondents and $25(83.3 \%)$, $101(43.0 \%)$ and 20(42.6\%) of women respondents were Diploma, Bachelor degree, Masters Degree holders respectively. The chi-square test result indicated that the existing difference in educational status between women and men respondents groups were found to be statistically significant at $1 \%$ level of significance. Based on this result, more women were found at the lower level of educational status, Diploma level. But their number decreased as we go up to the higher educational level, Bachelor and Masters degrees. At both Bachelor and 
Masters degrees level number of men were more than women.

Though there was statistically significant difference between women and men respondents in their educational status, based on above findings, there was no statistically significant work experience or work position difference to justify the existing difference in educational status.

Table 1: Chi-Square Test

\begin{tabular}{|c|c|c|c|c|c|c|c|}
\hline \multirow[t]{2}{*}{ NO. } & \multirow[t]{2}{*}{ Characteristics } & & \multicolumn{2}{|c|}{ Sex } & \multirow[t]{2}{*}{ Total } & \multirow[t]{2}{*}{ df } & \multirow[t]{2}{*}{$\mathrm{X} 2$} \\
\hline & & & $\begin{array}{c}\text { Men } \\
(\mathrm{N}=166)\end{array}$ & $\begin{array}{c}\text { Female } \\
(\mathrm{N}=146)\end{array}$ & & & \\
\hline \multirow[t]{4}{*}{1} & \multirow[t]{3}{*}{ Educational status } & Diploma & $5(16.7 \%)$ & $25(83.3 \%)$ & $30(100.0 \%)$ & \multirow{4}{*}{2} & \multirow{4}{*}{$17.80^{* * *}$} \\
\hline & & $\begin{array}{l}\text { Bachelor } \\
\text { degree }\end{array}$ & $134(57.0 \%)$ & $101(43.0 \%)$ & $235(100.0 \%)$ & & \\
\hline & & $\begin{array}{l}\text { Masters } \\
\text { degree }\end{array}$ & $27(57.4 \%)$ & $20(42.6 \%)$ & $47(100.0 \%)$ & & \\
\hline & Total & & $166(53.2 \%)$ & $146(46.8 \%)$ & $312(100.0 \%)$ & & \\
\hline \multirow[t]{4}{*}{2} & Work position & Junior expert & $22(48.9 \%)$ & $23(51.1 \%)$ & $45(100.0 \%)$ & \multirow{4}{*}{2} & \multirow{4}{*}{$5.04(\mathrm{~ns})$} \\
\hline & & Expert & $46(45.5 \%)$ & $55(54.5 \%)$ & 101(100.0\%) & & \\
\hline & & senior expert & $97(59.1 \%)$ & $67(40.9 \%)$ & $164(100.0 \%)$ & & \\
\hline & Total & & $165(53.2 \%)$ & $145(46.8 \%)$ & $310(100.0 \%)$ & & \\
\hline \multirow[t]{6}{*}{3} & Work experience by & under 1 & $42(53.8 \%)$ & $36(46.2 \%)$ & $78(100.0 \%)$ & \multirow{6}{*}{4} & \multirow{6}{*}{$1.63(\mathrm{~ns})$} \\
\hline & year & $1-5$ & $81(54.7 \%)$ & $67(45.3 \%)$ & $148(100.0 \%)$ & & \\
\hline & & $6-10$ & $23(46.9 \%)$ & $26(53.1 \%)$ & $49(100.0 \%)$ & & \\
\hline & & $11-15$ & $6(60.0 \%)$ & $4(40.0 \%)$ & $10(100.0 \%)$ & & \\
\hline & & $>15$ & $9(45.0 \%)$ & $11(55.0 \%)$ & $20(100.0 \%)$ & & \\
\hline & Total & & $161(52.8 \%)$ & $144(47.2 \%)$ & $305(100.0 \%)$ & & \\
\hline
\end{tabular}

Source: own computation

Desired Aspiration by Sex

HO1: There is no statistically significant difference in desired aspiration to management position between men and women

Table 2 showed that the mean value of desired aspiration for men and women groups were 3.99 and 3.77 respectively. According to this study finding, though men's desired aspiration was greater than that of women's, there is no statistically significant difference in desired aspiration between the two groups. This indicated that both women and men give the same value for management position. And there is no evidence to reject our hypothesis. And this finding is inline with the previous reaserch done by Hudson (2008).

Enacted Aspiration by Sex

$\mathrm{HO} 2$ : There exist statistically significant difference in enacted aspiration to management position between men and women

The mean values of enacted aspiration for women and men respondents were found to be 3.20 and 3.36 respectively (Table 2). This shows that men have greater enacted aspiration than women's and the difference was statistically significant at 5\% level of significance. And this finding was inline with the hypothesis. Based on this result, even though both men and women have the same value for management positions, men engaged in actions or strategies to peruse management positions more than women.

Previous study indicated that discrimination or anticipated discrimination and on the other hand, the lack of female role models and mentors may impact women negatively not to engaged in strategies to pursue management positions like that of men even though they have the same desired aspiration (Hudson, 2011).

\section{Self-Management Positions Congruence (Compatibility with management positions) by Sex}

Men's self- management positions congruence or compatibility with management positions was greater than women's congruence with the mean value of (3.25) and (3.04) respectively (Table 2). And there existed statistically significant difference between male and female groups regarding self-management Positions congruence at $5 \%$ level of significance. Based on this result, women perceived themselves less compatible to attain management positions than men.

The existing difference in life role priorities between men and women may reflect the incompatibility for females between their roles and responsibilities at home and those required of a management position. Since females are primarily responsible for the care of the household and the children they will feel that their lifestyles are less compatible with the lifestyles of individuals in management positions. (Friedman \& Greenhaus, 2000).

In addition, even though researchers have found that the essential ingredients of leadership and found no gender differences in leadership effectiveness (Hyde, 2014), the concept of leadership has been infused with stereotypically masculine traits: aggression, decisiveness, willingness to engage in conflict, strength, and so on. 
And these stereotypes make women to perceive themselves as less compatible compared to men.

Advancement Prospect to Management Positions (Accessibility to Management Positions) by Sex

Advancement prospects refer to the beliefs an individual holds about the likelihood and availability of attaining a promotion into the management position of an organization. Table 2 indicated that men have more advancement prospect with the mean values of (2.92) than females (2.68). And the difference was statistically significant at $5 \%$ significance level.

Self-perceived advancement opportunities or expectations have been found to be positively related to advancement aspirations (Greenhaus et al., 1997). Among those individuals who desire to attain a management position, the intention to pursue such a position may be affected by perceived advancement prospects within a particular organization.

Table 2: Advancement Prospect by Sex

\begin{tabular}{ccccc}
\hline Characteristics & $\begin{array}{c}\text { female } \mathbf{N = 1 4 6} \\
\text { mean }(\text { Std) }\end{array}$ & $\begin{array}{c}\text { male } \mathbf{N}=\mathbf{1 6 6} \\
\text { mean(Std) }\end{array}$ & df & t-value \\
\hline Enact_Asp & $1.63(0.51)$ & $1.76(0.49)$ & 310.00 & $2.31^{* *}$ \\
Self_Cong & $1.32(0.67)$ & $1.52(0.59)$ & 310.00 & $2.78^{* *}$ \\
Advace_Pros & $1.01(1.01)$ & $1.24(1.00)$ & 310.00 & $2.00^{* *}$ \\
Ocup_Com & $3.14(0.84)$ & $2.88(0.92)$ & 310.00 & $-2.49^{* *}$ \\
Desired_ASP & $0.68(0.29)$ & $0.75(0.30)$ & 310.00 & $1.88(\mathrm{~ns})$ \\
\hline
\end{tabular}

$* * *, * *$, and $*$ significant at $1 \%, 5 \%$ and $10 \%$ probability levels respectively, ns $=$ not significant

Source: own computation

Regression Results of the Causal Model

The Effect of desired aspiration on enacted aspiration moderated by sex

HO3: The positive effect of desired aspirations on enacted aspirations is stronger for men than for women.

Desired aspiration had statistically significant positive effect on enacted aspiration for both men and women professionals. But its effect was stronger for men professionals at $1 \%$ level of significance than for women, at $5 \%$ level of significance (Figure 1). Based on this finding HO3 was supported.

The Effect of Self-Management Position Congruence, Perceived Advancement Prospect and Occupational Commitment on Desired Aspirations moderated by sex

HO4: The positive effect of independent variables (perceived self-management position congruence, occupational commitment and advancement prospect) on the dependent variable, desired aspiration is stronger for men than women.

Figure 1 below depicted that self- management position congruence had positive and statistically significant effect on desired aspiration for both male and female at $1 \%$ level of significance. And in terms of the effect size, the effect was stronger for female than male with the beta value of 0.68 and 0.579 for female and male respectively.

Occupational commitment had positive and statistically significant effect on desired aspiration for males with the beta value of 0.235 at $1 \%$ level of significance. But the effect was not significant for females. And perceived advancement prospect had no significant effect on desired aspiration for both male and female (see figure 1). And based on these study findings, HO4 was partially supported.

The Effect of Self-Management Position Congruence, Perceived Advancement Prospect and Occupational Commitment on Enacted Aspirations moderated by sex

HO5: The positive effect of independent variables (perceived self-management position congruence, occupational commitment and advancement prospect) on the dependent variable, enacted aspiration is stronger for men than women.

Based on figure 1 below, perceived advancement prospect had positive and statistically significant effect on enacted aspiration for male with the beta value of 0.166 at $10 \%$ level of significance. But the effect was not significant for female.

Occupational commitment had positive and statistically significant effect on enacted aspiration for female with the beta value 0.21 at $10 \%$ level of significance. But the effect was not significant for male. And the effect of self-management position congruence on enacted aspiration was not statistically significant for both male and female (see figure 1). And based on these study findings, HO5 was partially supported. 
Figure-1: Causal Model of Structural Equation modeling

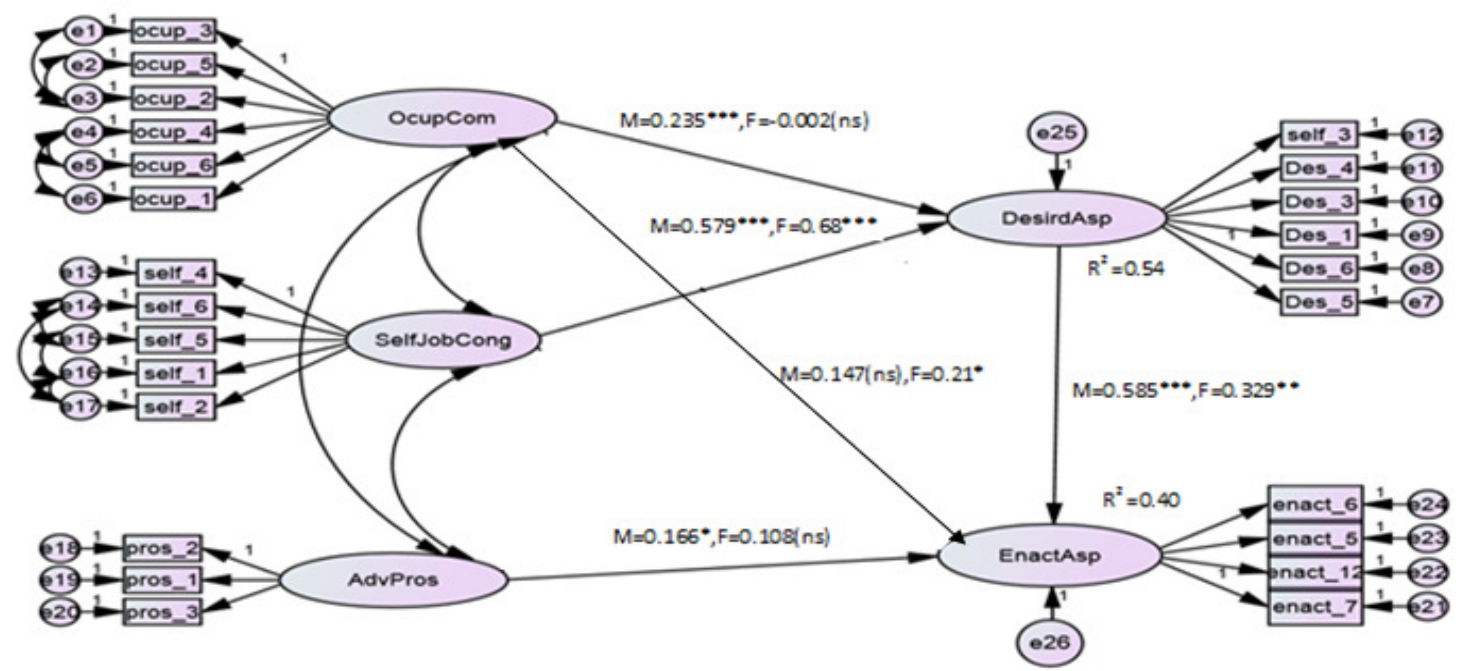

$* * *, * *$, and $*$ significant at $1 \%, 5 \%$ and $10 \%$ probability levels respectively, ns=not significant, $\mathrm{M}=\mathrm{Male}$, $\mathrm{F}=$ Female, Only significant lines were reported

Source: own computation

HO6: Desired aspiration mediates the relationship between the independent variables (perceived selfmanagement position congruence, occupational commitment and advancement prospect) on the dependent variable, enacted aspiration for both men and women.

The mediation effect of desired aspiration in the relationship between self- management position congruence and enacted aspiration

The effect of self-management position congruence on enacted aspiration was fully indirect, through desired aspiration for both men and women professionals. And based on the finding, indirect effect of self-management position congruence on enacted aspiration was stronger for men, at $1 \%$ level of significance than for women, at $5 \%$ level of significance (Table 3 ). And based on these study findings, HO6 was supported.

The mediation effect of desired aspiration in the relationship between occupational commitment and enacted aspiration

The effect of occupational commitment on enacted aspiration was not mediated by desired aspiration at $95 \%$ confidence interval (Table 3). And based on these study findings, HO5 was partially supported.

Table-3: Mediated Moderation Test of Indirect Effect

\begin{tabular}{llll}
\hline \multicolumn{1}{c}{ Path name } & $\begin{array}{c}\text { Direct Beta without } \\
\text { mediator }\end{array}$ & $\begin{array}{c}\text { Direct Beta with } \\
\text { mediator }\end{array}$ & Indirect Beta \\
\hline Enact_Asp $\leftarrow$ Ocup_Comm & $.050(\mathrm{~ns})$ & $0.147(\mathrm{~ns})$ & $0.082^{*}$ \\
Enact_Asp $\leftarrow$ Self_Congr & $-.084(\mathrm{~ns})$ & -0.005 (ns) & $0.331^{* * *}$ \\
\hline Path name & For Female Group & Indirect Beta \\
\hline Direct Beta without & Direct Beta with & mediator & \\
\hline Enact_Asp $\leftarrow$ Ocup_Comm & $.184^{*}$ & $0.21^{*}$ & $0.001(\mathrm{~ns})$ \\
Enact_Asp $\leftarrow$ Self_Congr & $.142(\mathrm{~ns})$ & $0.285(\mathrm{~ns})$ & $0.200^{* *}$ \\
\hline
\end{tabular}

*****, and $*$ significant at $1 \%, 5 \%$ and $10 \%$ probability levels respectively, ns=not significant

Source: own computation

\section{CONCLUSION AND RECOMMENDATION}

Conclusion

Professional women in the public service, even though they have the same desire with that of their men counter parts for management positions, they are not engaged enough in actions and strategies that help them to realize their desire and be in management positions due to various reasons.

Women were less likely than men to see themselves in terms that were congruent with management 
positions and they perceived themselves as they are not compatible with management position and this mainly contribute for their low enacted aspiration. From the prior studies, this is mainly because since management positions dominated by men, women are victim of the stereotypes that the field management is the men's world characterized by masculine traits: aggression, decisiveness, willingness to engage in conflict, strength, and so on. In addition since women are responsible for the care of the household and the children they will feel that their lifestyles are less compatible with the lifestyles of individuals in management positions.

\section{Recommendations}

Based on the major findings of the study, the following recommendations are given for Organizations to promote women's aspiration to management positions and make women equally participate in management positions at all levels.

- Organizations in collaboration with media should work on promoting role model women managers in their organizations. This will help to break the stereotypes and make men and women accept women can also be a good manager like men.

- One of the reasons why women think they are not fit to management positions is because they don't have the opportunity to test their skills on these positions. Organizations should give the opportunity for women to practice and test their skill on management positions by delegating them when managers are not around. In addition to this, the experience that woman's get though delegation need to be considered as management position experience while competing for management positions.

- Designing special succession plan for women this will enable organizations to build women's capacity in a planned manner so that to bridge the skill gaps.

- Make women to be coached and mentored by women managers even from different organizations; and

- Organizing women and establishing a forum for women to share their experiences and to solve challenges that they are facing on their way to management positions.

- Focusing on competences rather than setting excessive educational qualification and work experience as a requirement for management positions.

- Create conducive work environment and flexible working time for women so that they can fulfill both their work and household responsibilities.

\section{REFERENCES}

Bentler, P. M., \& Chou, C. P. (1987) Practical issues in structural modeling. Sociological Methods \& Research, 16, 78-117.

Field, A. (2000). Discovering Statistics using SPSS for Windows. London - Thousand Oaks - New Delhi: Sage publications.

Bartlett, M. S. (1954). A note on the multiplying factors for various chi square approximation. Journal of Royal Statistical Society, 16(Series B), 296-8.

Pallant, J. (2013). SPSS Survival Manual. A step by step guide to data analysis using SPSS, 4th edition. Allen \& Unwin,

Tabachnick, B. G. \& Fidell, L. S. (2007). Using multivariate statistics: Chicago: Univesity of Chicago Press.

Hair JF, Black WC, Babin BJ, Anderson RE (2006) Multivariate Data Analysis. Analysis 4-4.

Anderson EW, Fornell C, Lehmann DR (1994) Customer Satisfaction, Market Share, and Profitability: Findings from Sweden. Journal of Marketing 58: 53-66.

Anderson JC, Gerbing DW (1992) Assumptions and Comparative Strengths of the Two-Step Approach: Comment on Fornell and Yi. Sociological Methods \& Research 20: 321-333.

Amos C, Holmes GR, Keneson WC (2014) A meta-analysis of consumer impulse buying. Journal of Retailing and Consumer Services 21: 86-97.

Hu, L., Bentler, P.M. (1999), "Cutoff Criteria for Fit Indexes in Covariance Structure Analysis: Conventional Criteria Versus New Alternatives" SEM vol. 6(1), pp. 1-55.

Hair, J., Black, W., Babin, B., and Anderson, R. (2010). Multivariate data analysis (7th ed.): Prentice-Hall, Inc. Upper Saddle River, NJ, USA.

Vanhala (2011) 'Career orientations of women middle managers' In: Husu, L., Hearn, J., Lämsä, A-M., and Vanhala, S., W0men, Management and Leadership - Naiset ja johtajuus. Hanken School of Economics Research Reports

Vanhala, S. Pesonen, S. (2008) 'Työstä nauttien: SEFE:en kuuluvien nais- ja miesjohtajien näkemyksiä työstään ja urastaan'

Gottfredson, L. S. (1981). Circumscription and compromise: A developmental theory of occupational aspirations. Journal of Counseling Psychology, 28(6), 545-579.

Gottfredson, L. S. (1996). Gottfredson's theory of circumscription and compromise. Career choice and 
development (3rd ed.). San Francisco, CA: Jossey-Bass.

Cochran, W.G. (1963) Sampling Technique. 2nd Edition, John Wiley and Sons Inc., New York.

Allen, \& Meyer. (1996). Affective, Continuance, and Normative Commitment to the Organization: An Examination of Construct Validity. Journal of Vocational Behavior, 49(3), 252-276.

Allen, N. J., \& Meyer, J. P. (1990). The measurement and antecedents of affective, continuance and normative commitment to the organization. Journal of Occupational Psychology, 63(1), 1-18.

Allen, N. J., \& Meyer, J. P. (2000). Construct validation in organizational behavior research: The case of organizational commitment. In R. D. Goffin \& E. Helme (Eds), Problems and solutions in human assessment: Honouring Douglas N. Jackson at seventy (pp 285-314). Norwell, MA: Kluwer.

Baruch, Y. (2004). Managing Careers: Theory and Pratice. Harlow: FT-Prentice Hall/Pearson.

Beck, J., \& La Lopa, J. M. (2001). An exploratory application of Schein's Career Anchors Inventory to Hotel Executive Operating Committee members. International Journal of Hospitality Management, 20(1), 15-28. 